\title{
The Written Competence of Spanish Secondary Education Students in Bilingual and Non-Bilingual Programs
}

\author{
Ana Cristina Lahuerta Martínez \\ Universidad de Oviedo
}

Received: 2 June 2014 / Accepted: 26 April 2015

ISSN: $1697-7467$

\begin{abstract}
The present study compares bilingual and non-bilingual program students' L2 written competence. Three hundred and ninety-three secondary education students participated in the study. The results obtained show that: (a) there are significant differences in written competence between the bilingual and the non-bilingual program groups, with the bilingual program group outperforming the non-bilingual program group; (b) the four measures used to assess writing (fluency, accuracy, lexical and grammatical complexity) develop in tandem; (c) bilingual programs may help to diminish the differences observed in favour of female students when learning a foreign language; and (d) there are significant relationships between all the writing measures studied.
\end{abstract}

Keywords: writing, fluency, accuracy, complexity, bilingual program.

La competencia escrita de estudiantes españoles de educación secundaria de programas bilingües y no bilingües

RESUMEN: Este estudio compara la competencia escrita en una lengua no nativa de estudiantes de programas bilingües y no bilingües. Un total de 393 estudiantes de educación secundaria obligatoria participaron en el estudio. Los resultados muestran que: (a) existe una diferencia significativa entre los grupos bilingüe y no bilingüe, a favor de los primeros; (b) las cuatro medidas utilizadas para evaluar la escritura (fluidez, precisión, complejidad gramatical y léxica) se desarrollan en paralelo; (c) los programas bilingües pueden ayudar a disminuir las diferencias a favor de las mujeres en el aprendizaje de una lengua extranjera; (d) se obtienen relaciones significativas entre todas las medidas utilizadas.

Palabras clave: escritura, fluidez, precisión, complejidad, programa bilingüe.

\section{INTRODUCTION}

Writing has been a useful tool to assess learners' language competence in a foreign language classroom. Written competence is a subset of learners' language competence, with an emphasis on writing-specific abilities such as the production of a variety of genres and rhetorical features, but also including language-specific abilities such as the use of a range of vocabulary and syntactic structures (Wolfe-Quintero, Inagaki and Kim, 1998: 2). As Weissberg (2000) states, writing seems to reflect better than speech the emergence of new morphosyntactic forms and the development of grammar. The written mode is one of the most 
widespread forms of recording bilingual program students' knowledge for assessment, both at national and international levels, in for example, the examinations to obtain the International General Certificate of Secondary Education (IGCSE). These examinations are based both on content and writing appropriately (see IGCSE mark schemes and examiner report, 2008).

Bilingual programs or the content and language integrated learning (CLIL) approach have been praised on many different grounds (Coyle, 2008; Marsh, 2008). CLIL is considered to be an alternative path to conventional English as a Foreign Language teaching. Bilingual programs are believed to foster implicit and incidental learning by focusing on meaning and communication, and as a result they are also believed to improve overall language competence in the target language (Lasagabaster, 2008).

As Babba and Nitta (2014) explain, L2 writing is a complex and elusive activity that can be viewed and conceptualized from multiple theoretical points, so it is difficult to even define the development of writing abilities. Following Larsen-Freeman (2006), we conceptualize language development as a complex dynamic process. Written competence as a subset of language competence is also complex and cannot be totally accounted for by performance in any one subsystem. In this study, written competence is characterised by three dimensions of language proficiency: fluency, accuracy and complexity. Research has shown that these three dimensions are robust indicators of a learner's written competence (Baba and Nitta, 2014; Wolfe-Quintero et al., 1998). We argue that these three characteristics of written language competence progress in tandem, so that more proficient foreign language writers are more fluent, accurate, and complex in their writing than less proficient ones.

The assessment of written competence and development is difficult. Wolfe-Quintero, Inagaki and Kim (1998) review several studies that have used measures of fluency, accuracy, grammatical complexity and lexical complexity to analyse written data in order to, for example, compare writers at different proficiency levels, or to examine the relationships between errors and holistic ratings of second language writers.

We follow this line of research and compare the written competence of third and fourth grade secondary education students enrolled on bilingual and non-bilingual programs. There has not been much work published to date specifically on the comparison of the written production of these two groups of students and this paper intends to shed some light on this question as well as on the more frequently approached one of the effectiveness of bilingual programs.

\section{A Review of the Literature}

Among the earliest studies, Carlisle (1989:257) examined the writing of Hispanic students in a bilingual program and compared their writing with that of Hispanic students in a submersion program and native English speakers in a regular program. The variables investigated were rhetorical effectiveness, overall quality of writing, productivity or total number of words written, syntactic maturity defined as the average number of words per T-units, and error frequency. Results revealed that the sixth graders had significantly higher scores than did the fourth graders on all the variables except for error frequency. However, the correlation was negative, indicating that older students tended to make fewer errors. An analysis of the correlation between measures showed that rhetorical effectiveness correlated 
significantly with the overall quality of writing, and that productivity, syntactic maturity and error frequency correlated significantly with rhetorical effectiveness and the overall quality of writing (1989:272-273).

Navés, Torras and Celaya (2003) investigated the effects of age on the levels of attainment in writing performance. They analyse the development of the written production of six groups of primary and secondary education learners. Among the main findings of this study are the following (2003:123-124): there seem to be two different patterns of development in EFL written production (accuracy, fluency, syntactic complexity and lexical complexity) depending on learners' age; (b) accuracy, fluency, syntactic and lexical complexity do not develop in tandem, but correlate differently depending on the learners' age group.

Ruiz de Zarobe (2008) examined foreign written competence in CLIL contexts. She compared the longitudinal written competence of CLIL and non-CLIL students in the third and fourth year of Secondary Education and in the second year of post-compulsory Secondary Education (Baccalaureate). Students' written competence was tested through compositions scored using the categories content, organization, vocabulary, language use and mechanics. The results showed that the CLIL groups outperformed the non-CLIL groups in most of the scales analysed although these differences were significant only in relation to content and vocabulary (2008:67).

Lasagabaster (2008) also examined foreign language competence including written competence in CLIL contexts. The sample used include a group made up of non-CLIL students in the fourth year of secondary education, another group made of CLIL students in the fourth year of secondary education and a third group made up of CLIL students in the third year of secondary education. Competence in the foreign language was measured via four English tests corresponding to grammar, listening, speaking and writing (2008: 35). Results (2008:36-38) revealed that the CLIL groups significantly outperformed their non-CLIL counterparts in every single test and in the overall English competence score. Besides, the CLIL approach had a clear impact on all the language skills and the grammar test analysed in this study when students enrolled in the same grade were compared. The third year CLIL group not only did catch up with their fourth year non-CLIL counterparts and but also surpassed them in overall foreign language competence.

Navés and Victori (2010) carried out two studies produced in a CLIL environment with CLIL and non-CLIL learners from two primary and three secondary schools. They focused on the subjects' general language proficiency and learners' writing skills. Students' language proficiency was analysed by means of a listening test, a grammar test and a dictation in English. The writing test consisted of a composition, which was analysed for accuracy, fluency, syntactic complexity and lexical complexity (2010:34). Results of both studies showed that CLIL learners outperformed non-CLIL learners in most of the tests administered (2010:4143). The first study also found that seventh grade CLIL learners obtained results similar to those of non-CLIL learners one or two grades ahead for each of the measures analysed: dictation, reading comprehension, grammar and listening skills. In the second study, CLIL learners' writing at lower grades was observed to be as good as or even better than that of older learners a few grades ahead. From both studies the authors conclude (2010:47) that when learners are at grades 7 and 9 and have received CLIL instruction they achieve a level equivalent to or even higher than learners a couple of grades ahead in many of the domains of a language. 
Whittaker et al. (2011) present a study of written development in English as a foreign language produced in a CLIL environment. The aim was to identify the linguistic resources used to create coherence and appropriate register in the CLIL students' written texts. Texts from history classes were collected annually over the four-year obligatory secondary education program from the same students (aged 12 to 16), in two schools (2011:348). Results (2011:358) showed development in the control of textual resources, and some increase in nominal group complexity, over the four years. These authors conclude that CLIL settings provide suitable contexts in which to develop written discourse.

Merisuo-Storm and Soininen (2014:75) carried out a longitudinal study on the effects of CLIL on the development of children's literacy skills from the first to the sixth grade. The test group studied, from the first grade, different school subjects in Finnish and in English. The students in the control group studied all school subjects in Finnish and started to learn English as a second language in third grade (2014:71). The writing task consisted of writing a story. Results showed that after two study years, the writing skills of the test group were significantly better than those of the control group. After four school years the children's creative writing skills had also benefited from bilingual teaching (2014:78).

Lorenzo and Rodríguez (2014:64) approached the evolution of academic language structures in a second language, in formal bilingual contexts. The authors analysed a corpus of historical narratives of subjects from the third year of Secondary Education to the second year of post-compulsory Secondary Education (Baccalaureate) from 4 secondary schools where a CLIL approach was set up. Results (2014:68) showed that learners in the lowest grades in a CLIL setting produced an amalgamated language, characterized by a lack of dependent clauses, t-units and coordinate phrases. However, this language skill was consolidated in higher grades. As these authors (2014:71) conclude, CLIL contexts in these grades and settings enhance the complex, discursive, academic functions, as expressed in narratives.

Some other recent studies compare writers' competence development at different instruction periods. Godfrey and Treacy (2014) examined the writing of eight university learners of French - four during study abroad and four in on-campus courses - over the course of a semester. This study applied measures focused on the complexity, accuracy, fluency, and formfunction relationships of writing samples collected at the beginning and end of the semester (2014:52-54). Results (2014:56) suggested that progress toward more advanced academic L2 writing occurred for both groups of students, although in different ways. For example, on a measure of accuracy, the study abroad group increased both their use of French gendered nouns and their accuracy in gender marking more than the on-campus group did. A T-unit analysis showed that, while both groups increased the syntactic complexity in their writing, the domestic group improved more than the study abroad group did.

\section{Aims of The Study}

The literature reviewed above shows that students that follow bilingual programs tend to obtain better results in written competence. Moreover, the analysis of the writing measures used to assess such competence shows significant differences among course levels and reveal improvement over time. The present study wants to contribute to this line of research in a different instruction context and aims to analyse and compare the written competence of two 
groups of secondary education students: one enrolled on a bilingual program and another group enrolled on a non-bilingual program, including in the analysis grade and gender. Written competence is characterised, as stated above by three dimensions of language proficiency: fluency, accuracy and complexity. We assume that foreign language writers will write more fluently, or write more in the same amount of time, write more accurately, or produce fewer errors in their writing, and write more grammatically and lexically complex sentences as they become more proficient. The following research questions are the focus of the study:

Question 1: Is there a significant difference in written competence between the bilingual and the non-bilingual groups?

Question 2: Is there a significant difference in written competence between the third and fourth year groups?

Question 3: is there a significant difference in writing competence between men and women?

Question 4: What will the relationship be between the measures in the areas of fluency, accuracy, lexical complexity and grammatical complexity and accuracy?

\section{4. Меthod}

\subsection{Participants}

The participants were 399 secondary education students enrolled in seven different state schools in Asturias. They had started learning English at the age of five. The sample was divided into four groups: Two groups of students enrolled on a bilingual program, consisting of a first group made up of 101 students in the third year of compulsory education and a second group made up of 104 students in the fourth year of compulsory education. Two groups of students who did not follow a bilingual program, which consisted of a group of 98 students in the third year of compulsory education, and a group of 90 students in the fourth year of compulsory education. Of the total of students, 190 were men and 194 women. The English proficiency level of the students ranged from A1 to A2 on the basis of the Council of Europe's Common European Framework of Reference of Languages (CEFR).

The students enrolled on bilingual programs have two and a half hours a week of English in the first and second year of primary education and three hours a week from third to sixth year. They also have two hours a week of a content subject taught in English (total number of hours in primary education: 972). In secondary education, they have five hours of English a week from first to fourth year. In addition, they also have three hours a week of a content subject taught through English (total number of hours in secondary education: 1008).

On the other hand, those students enrolled on non-bilingual programs have two hours a week of English in the first and second year of primary education, two and a half in third and fourth year and three hours a week from fifth to sixth (total number of hours in primary education: 540). They have four hours of English a week from first to third year of compulsory secondary education and three hours in fourth year of compulsory secondary education (total number of hours in secondary education: 540). (BOPA num.21, 27/05/2009). 


\subsection{Procedure}

For the present study, the data come from a written composition activity, which was administered to participants in their own classroom. For the written activity, students had to write on the topic 'Do you think school uniform should be worn at the high school?' All the participants were given 30 minutes for the activity. In this way, time and topic constraints were controlled to make results comparable (Wolfe-Quintero et al. 1998).

The writing measures used to analyse the written production of the four groups of learners have been classified into four areas following Wolfe-Quintero et al. (1998): fluency, accuracy, grammatical complexity and lexical complexity. To measure fluency we counted the total number of words. In addition, we used sentence length (total number of words divided by total number of sentences) as a measure of the fluency of writing. For accuracy, the measures used were error-free sentence ratio (total number of error-free sentences divided by total number of sentences) and errors per word ratio (total number of errors divided by total number of words). Regarding the grammatical complexity measures, we used the sentence complexity ratio (total number of sentences divided by total number of clauses). As an additional measure, we also counted the total number of connectors in the writing samples. Finally, for lexical complexity we used the ratio of the number of word types to the square root of two times the word tokens.

\subsection{Results}

A statistical analysis was carried out with the program $\mathrm{R}$ Development Core Team 2012, version 2.15. In what follows, we will see the results obtained for each research question formulated.

Research Question 1: Is there a significant difference in written competence between the bilingual program and the non-bilingual program groups?

Results revealed significant differences between the bilingual and non-bilingual program groups. The bilingual program group significantly outperformed the non-bilingual program group in the general quality of the composition, in three areas of writing (accuracy, fluency and lexical complexity) and in one measurement of grammatical complexity. The bilingual group obtained a higher mean for the composition score $(\mathrm{M}=5.95 ; \mathrm{M}=3.78$, Welch test, $\mathrm{p}<0.001)$. Moreover, bilingual program students' fluency in writing as measured by the total number of words was significantly higher than that of non-bilingual program students $(\mathrm{M}=102.25 ; \mathrm{M}=65.38$, Welch test, $\mathrm{p}<0.001)$. In addition, bilingual program students also significantly outperformed non-bilingual program students in sentence length measured as the total number of words per sentence $(M=20.75$; $M=15.91$, Welch test, $\mathrm{p}<0.001)$. Bilingual program students' accuracy in writing as measured by the percentage of error-free sentences and by errors per word ratio was significantly higher than that of non-bilingual program students $(\mathrm{M}=0.35 ; \mathrm{M}=0.18$, Welch test, $\mathrm{p}<0.001 ; \mathrm{M}=0.07 ; \mathrm{M}=0.18$, Welch test, $\mathrm{p}<0.001)$. The bilingual group significantly outperformed the non-bilingual group in the lexical complexity measure $(\mathrm{M}=1.46 ; \mathrm{M}=1.18$, Student's t-test $\mathrm{p}<0.001)$. Grammatical complexity measures gave mixed results. While bilingual program students significantly outperformed non-bilingual program students in one grammatical complexity indicator (the total number of connectors) $(\mathrm{M}=3.78 ; \mathrm{M}=2.07$, Welch test, $\mathrm{p}<0.001)$, the non-bilingual group obtained a higher mean 
$(\mathrm{M}=0.57 ; \mathrm{M}=0.46$, Welch test, $\mathrm{p}<0.001)$ in the sentence complexity ratio as measured as the total number of sentences per clause.

Research Question 2: Is there a significant difference in written competence between third and fourth grade students?

The second major goal of this study was to find the development of writing measures within the groups. The results showed a trend of development in written competence from third to fourth grade in both groups. Table 1 indicates that, in the bilingual group, fourth graders significantly outperform third graders in the general quality of the composition $(M=6.37$, Welch test, $\mathrm{p}<0.001$ ), and in the two measures of fluency in writing, i.e., total number of words $(\mathrm{M}=115.50$, Student's t-test, $\mathrm{p}<0.001)$, and sentence length $(\mathrm{M}=21.73$, Student's ttest, $\mathrm{p}<0.03$ ). This trend is also observed in the two measures of accuracy in writing, i.e. percentage of error-free sentences $(\mathrm{M}=0.42$, Student's t-test, $\mathrm{p}<0.001)$ and errors per word ratio $(M=0.05$, Student's t-test, $\mathrm{p}<0.001)$. Fourth graders also outperform third graders in lexical complexity $(\mathrm{M}=1.60$, Student's t-test $\mathrm{p}<0.001)$ and with respect to grammatical complexity, fourth graders outperform third graders in the total number of connectors $(M=4.11$, Student's t-test, $\mathrm{p}<0.04)$. However, third graders outperform fourth graders in the sentence complexity ratio $(\mathrm{M}=0.49$, Student's t-test $\mathrm{p}<0.001)$.

In the non-bilingual group, we observe that fourth graders significantly outperform third graders in the general quality of the composition $(\mathrm{M}=4.79$, Welch test, $\mathrm{p}<0.001)$, in the two measures of fluency in writing, i.e., total number of words $(M=93.11$, Student's t-test, $\mathrm{p}<0.001)$, and sentence length $(\mathrm{M}=19.30$, Student's t-test, $\mathrm{p}<0.001)$, in accuracy in writing as measured by the percentage of error-free sentences $(M=0.22$, Student's t-test, $p<0.04)$ and as measured by errors per word ratio $(\mathrm{M}=0.12$, Student's t-test, $\mathrm{p}<0.001)$, and in lexical complexity $(\mathrm{M}=1.30$, Student's t-test $\mathrm{p}<0.001)$. Regarding, grammatical complexity, fourth graders outperform third graders in the total number of connectors $(M=2.78$, Student's t-test, $\mathrm{p}<0.001)$. However, third graders outperform fourth graders in the sentence complexity ratio $(\mathrm{M}=0.65$, Student's t-test $\mathrm{p}<0.001)$. 
Table 1 Bilingual and non-bilingual program third and fourth grade students'written competence

\begin{tabular}{|c|c|c|c|c|}
\hline & Year & Mean & SD & $\mathbf{P}$ \\
\hline \multirow[t]{6}{*}{ Composition score } & Bilingual & & & \\
\hline & Fourth & 6.37 & 1.98 & 0.01 \\
\hline & Third & 5.50 & 2.73 & \\
\hline & Non-bilin. & & & \\
\hline & Fourth & 4.79 & 2.76 & 0.001 \\
\hline & Third & 2.85 & 2.59 & \\
\hline \multirow[t]{6}{*}{ Total Num. words } & Bilingual & & & \\
\hline & Fourth & 115.50 & 51.73 & 0.001 \\
\hline & Third & 88.47 & 46.99 & \\
\hline & Non-bilin. & & & \\
\hline & Fourth & 93.11 & 67.48 & 0.001 \\
\hline & Third & 39.90 & 39.37 & \\
\hline \multirow[t]{6}{*}{ Sentence length } & Bilingual & & & \\
\hline & Fourth & 21.73 & 6.85 & 0.03 \\
\hline & Third & 19.71 & 5.93 & \\
\hline & Non-bilin. & & & \\
\hline & Fourth & 19.30 & 6.55 & 0.001 \\
\hline & Third & 12.78 & 5.51 & \\
\hline \multirow[t]{6}{*}{ Error-free sent. ratio } & Bilingual & & & \\
\hline & Fourth & 0.42 & 0.37 & 0.001 \\
\hline & Third & 0.27 & 0.32 & \\
\hline & Non-bilin. & & & \\
\hline & Fourth & 0.22 & 0.28 & 0.04 \\
\hline & Third & 0.14 & 0.26 & \\
\hline \multirow[t]{6}{*}{ Errors per word ratio } & Bilingual & & & \\
\hline & Fourth & 0.05 & 0.05 & 0.001 \\
\hline & Third & 0.08 & 0.06 & \\
\hline & Non-bilin. & & & \\
\hline & Fourth & 0.12 & 0.10 & 0.001 \\
\hline & Third & 0.23 & 0.18 & \\
\hline \multirow[t]{6}{*}{ Sentence comp. ratio } & Bilingual & & & \\
\hline & Fourth & 0.42 & 0.14 & 0.001 \\
\hline & Third & 0.49 & 0.17 & \\
\hline & Non-bilin. & & & \\
\hline & Fourth & 0.49 & 0.17 & 0.001 \\
\hline & Third & 0.65 & 0.24 & \\
\hline \multirow[t]{6}{*}{ Num. connectors } & Bilingual & & & \\
\hline & Fourth & 4.11 & 2.19 & 0.04 \\
\hline & Third & 3.43 & 2.54 & \\
\hline & Non-bilin. & & & \\
\hline & Fourth & 2.78 & 1.93 & 0.001 \\
\hline & Third & 1.41 & 1.41 & \\
\hline \multirow[t]{6}{*}{ Word variation } & Bilingual & & & \\
\hline & Fourth & 1.60 & 0.47 & 0.001 \\
\hline & Third & 1.32 & 0.48 & \\
\hline & Non-bilin. & & & \\
\hline & Fourth & 1.30 & 0.39 & 0.001 \\
\hline & Third & 1.08 & 0.46 & \\
\hline
\end{tabular}


We also compared the bilingual third grade students and the third and fourth grade nonbilingual students. The students enrolled on third grade bilingual programmes scored higher than the non-bilingual fourth graders in all measures. Bilingual third graders significantly outperformed non-bilingual third and fourth graders in the general quality of the composition ( $\mathrm{M}=5.50$, Kruskal-Wallis test, $\mathrm{p}<0.001)$, in fluency in writing as measured by sentence length $(\mathrm{M}=19.71$, Kruskal-Wallis test, $\mathrm{p}<0.001)$, in accuracy in writing both as measured by the percentage of error-free sentences $(\mathrm{M}=0.27$, Kruskal-Wallis test, $\mathrm{p}<0.001)$ and as measured by errors per word ratio $(\mathrm{M}=0.08$, Kruskal-Wallis test, $\mathrm{p}<0.001)$, and in lexical complexity $(\mathrm{M}=1.32$, Kruskal-Wallis test, $\mathrm{p}<0.001)$. With respect to grammatical complexity bilingual third graders significantly outperformed non-bilingual third and fourth graders in the total number of connectors $(\mathrm{M}=3.43$, Kruskal-Wallis test, $\mathrm{p}<0.001)$. In sentence complexity ratio both bilingual third graders and non-bilingual fourth graders outperformed non-bilingual third graders $(\mathrm{M}=0.49$, Kruskal-Wallis test, $\mathrm{p}<0.001)$.

Research Question 3: is there a significant difference in writing between men and women?

When we distinguish by gender, we observe that women outperform men in the general quality of the composition in both groups, but when considering the writing measures, women outperform men in far more measures in the non-bilingual group.

As we can see in Table 2, in the bilingual program group, women outperform men in the general quality of the composition $(\mathrm{M}=6.38$, Student's t-test, $\mathrm{p}<0.04)$ and in one measure of grammatical complexity (total number of connectors used) ( $M=4.34$, Student's t-test, $\mathrm{p}<0.001)$.

In the non-bilingual group, women significantly outperform men in the general quality of the composition $(\mathrm{M}=4.50$, Student's t-test, $\mathrm{p}<0.001)$, in fluency measured as the total number of words $(M=81.34$, Student's t-test, $\mathrm{p}<0.001)$, and measured as sentence length $(\mathrm{M}=17.76$, Student's t-test, $\mathrm{p}<0.001)$. Women also significantly outperform men in one measurement of accuracy, i.e. errors per word ratio $(M=0.15$, Student's t-test, $p<0.02)$, in one measurement of grammatical complexity, i.e., the total number of connectors $(\mathrm{M}=2.58$, Student's t-test, $\mathrm{p}<0.001)$, and in lexical complexity $(\mathrm{M}=1.26$, Student's t-test, $\mathrm{p}<0.02)$. On the other hand, men significantly outperform women in the sentence complexity ratio $(\mathrm{M}=0.61$, Student's t-test, $\mathrm{p}<0.02)$. 
Table 2 Comparison of men and women's written competence

\begin{tabular}{|c|c|c|c|c|c|}
\hline & Group & Sex & Mean & SD & $\mathrm{P}$ \\
\hline \multirow[t]{4}{*}{ Composition score } & \multirow[t]{2}{*}{ Bilingual } & Men & 5.67 & 2.57 & \multirow[t]{2}{*}{0.04} \\
\hline & & Women & 6.38 & 2.13 & \\
\hline & \multirow[t]{2}{*}{ Non-bilingual } & Men & 3.15 & 2.63 & \multirow[t]{2}{*}{0.001} \\
\hline & & Women & 4.50 & 2.91 & \\
\hline \multirow[t]{4}{*}{ Total Num. words } & \multirow[t]{2}{*}{ Bilingual } & Men & 99.12 & 53.36 & \multirow[t]{2}{*}{0.12} \\
\hline & & Women & 110.64 & 47.88 & \\
\hline & \multirow[t]{2}{*}{ Non-bilingual } & Men & 51.62 & 48.30 & \multirow[t]{2}{*}{0.001} \\
\hline & & Women & 81.34 & 69.37 & \\
\hline \multirow[t]{4}{*}{ Sentence length } & Bilingual & Men & 20.94 & 6.87 & \multirow[t]{2}{*}{0.76} \\
\hline & Women & 21.22 & 5.91 & & \\
\hline & \multirow[t]{2}{*}{ Non-bilingual } & Men & 14.30 & 7.30 & \multirow[t]{2}{*}{0.001} \\
\hline & & Women & 17.76 & 6.85 & \\
\hline \multirow[t]{4}{*}{ Error-free sent $r$. } & \multirow[t]{2}{*}{ Bilingual } & Men & 0.35 & 0.37 & \multirow[t]{2}{*}{0.61} \\
\hline & & Women & 0.37 & 0.34 & \\
\hline & \multirow[t]{2}{*}{ Non-bilingual } & Men & 0.17 & 0.26 & \multirow[t]{2}{*}{0.51} \\
\hline & & Women & 0.19 & 0.28 & \\
\hline \multirow[t]{4}{*}{ Errors per word $\mathrm{r}$. } & \multirow[t]{2}{*}{ Bilingual } & Men & 0.07 & 0.06 & \multirow[t]{2}{*}{0.18} \\
\hline & & Women & 0.06 & 0.05 & \\
\hline & \multirow[t]{2}{*}{ Non-bilingual } & Men & 0.20 & 0.17 & 0.02 \\
\hline & & Women & 0.15 & & 0.14 \\
\hline \multirow[t]{4}{*}{ Sentence comp. r. } & \multirow[t]{2}{*}{ Bilingual } & Men & 0.46 & 0.19 & \multirow[t]{2}{*}{0.27} \\
\hline & & Women & 0.44 & 0.12 & \\
\hline & \multirow[t]{2}{*}{ Non-bilingual } & Men & 0.61 & 0.23 & \multirow[t]{2}{*}{0.02} \\
\hline & & Women & 0.53 & 0.21 & \\
\hline \multirow[t]{4}{*}{ Num. connectors } & \multirow[t]{2}{*}{ Bilingual } & Men & 3.33 & 2.17 & 0.001 \\
\hline & & Women & 4.34 & 2.48 & \\
\hline & Non-bilingual & Men & 1.63 & 1.63 & 0.001 \\
\hline & & Women & 2.58 & 1.88 & \\
\hline Word variation & Bilingual & Men & 1.41 & 0.50 & 0.13 \\
\hline & & Women & 1.52 & 0.50 & \\
\hline & Non-bilingual & Men & 1.12 & 0.46 & 0.02 \\
\hline & & Women & 1.26 & 0.41 & \\
\hline
\end{tabular}

Research Question 4: What will the relationship be between the measures in the areas of fluency, accuracy, lexical complexity and grammatical complexity and accuracy?

A further aim of this study was to find out how the different measures of writing ability correlated with each other. All the variables turned out to be associated significantly with the global score, except for sentence length in the bilingual group (Composition score -Number 
of words: bilingual $p 0.71$ pvalue $<0.001$; non-bilingual $p 0.73$ pvalue $<0.001$; Composition score-Sentence length: bilingual $p 0.11$ pvalue 0.1206 ; non-bilingual $p 0.63$ pvalue $<0.001$; Composition score-Error-free sentence ratio: bilingual $p 0.68$ pvalue $<0.001$; non-bilingual $p$ 0.57 pvalue $<0.001$; Composition score-Errors per word ratio: bilingual $p 0.76$ pvalue $<0.001$; non-bilingual $p-0.68$ pvalue $<0.001$; Composition score-Sentence complexity ratio: bilingual $p-0.26$ pvalue $<0.001$; non-bilingual $p-0.54$ pvalue $<0.001$; Composition score-Number of connectors: bilingual $p 0.59$ pvalue $<0.001$; non-bilingual $p 0.74$ pvalue $<0.001$; Composition score-Word variation: bilingual $p 0.60$ pvalue $<0.001$; non-bilingual $p 0.58$ pvalue $<0.001$ ). The relationship between total number of words, sentence length, error-free sentence ratio, number of connectors and lexical complexity with the global composition score was positive (when one increases, the score increases) in both groups. On the other hand, the relationship between errors per word ratio and sentence complexity ratio with the composition score is negative (when one of them increases the score decreases), in both groups as well.

With respect to the measures of written competence, we obtain significant relationships between all the pairs studied. The relationships were positive except for total number of words and errors per word ratio, sentence length and errors per word ratio, errors per word ratio and lexical complexity, error-free sentence ratio and sentence complexity ratio, errors per word ratio and sentence complexity ratio, number of words and sentence complexity ratio, sentence length and sentence complexity ratio and lexical complexity and sentence complexity ratio. These were negative (when one of them increases the other decreases).

Fluency-Accuracy: We find a significant correlation between total number of words and error-free sentence ratio $(p=0.45, \mathrm{p}<0.001)$ and between total number of words and errors per word ratio $(p=-0.60, \mathrm{p}<0.001)$. Sentence length is significantly correlated with errorfree-sentence ratio $(p=0.17, \mathrm{p}<0.001)$ and with errors per word ratio $(p=-0.56, \mathrm{p}<0.001)$. In other words, the more fluent learners are, the more accurate their writing may also be.

Accuracy and Lexical Complexity: Error-free sentences and errors per word ratio significantly correlate with lexical complexity $(p=0.46, \mathrm{p}<0.001 ; p=-0.51, \mathrm{p}<0.001)$. Accurate writers write more lexically complex texts.

Fluency and Lexical Complexity: Total number of words and sentence length significantly correlate with lexical complexity $(p=0.57, \mathrm{p}<0.001 ; p=0.32, \mathrm{p}<0.001)$. The longer the compositions the more lexically complex they are.

Accuracy and grammatical complexity: Error-free sentence ratio significantly correlates with sentence complexity ratio $(p=-0.16, \mathrm{p}<0.002)$ and total number of connectors $(p=0.44$, $\mathrm{p}<0.001$ ). In other words, the larger the number of sentences without errors the lower the number of clauses and the larger the number of connectors. Errors per word ratio significantly correlates with sentence complexity ratio $(p=0.52, \mathrm{p}<0.001)$ and total number of connectors $(p=-0.52, \mathrm{p}<0.001)$. The larger the number of errors the larger the number of clauses and the lower the number of connectors.

Fluency and grammatical complexity: Total number of words significantly correlate with sentence complexity ratio $(p=-0.48, \mathrm{p}<0.001)$ and total number of connectors $(p=0.70$, $\mathrm{p}<0.001)$. Sentence length significantly correlate with sentence complexity ratio $(p=-0.75$, $\mathrm{p}<0.001)$ and with total number of connectors $(p=0.47, \mathrm{p}<0.001)$. The longer the compositions the fewer the clauses and the larger the number of connectors. 
Lexical complexity and grammatical complexity: Lexical complexity significantly correlate with sentence complexity ratio $(p=-0.38, \mathrm{p}<0.001)$ and total number of connectors $(p=0.55, \mathrm{p}<0.001)$. The more lexically complex compositions have fewer clauses and larger number of connectors.

\section{Discussion}

In this study, we compared the written competence of a group of students enrolled on a bilingual program and another group enrolled on a non-bilingual program. What follows is a discussion of the main results.

1. There is a significant difference in written competence between the bilingual and the non-bilingual program groups. The bilingual group outperforms the non-bilingual group in the general quality of the compositions, in all the fluency, accuracy and lexical complexity measures and in one of the grammatical complexity measures of writing used. This supports previous results (e.g. Lasagabaster, 2008; Merisuo-Storm and Soininen, 2014; Navés and Victori, 2010; Ruiz de Zarobe, 2008) and points to the effectiveness of bilingual settings to develop written competence.

2. The comparison between third and fourth graders allows us to identify how the four indicators of writing proficiency develop within a school setting. Both the bilingual and the non-bilingual program fourth grade students outperform third graders in the general quality of the compositions as well as in the fluency, accuracy, grammatical and lexical complexity measures of writing used, with the exception of the sentence complexity ratio. These results are in line with those of Carlisle (1989), and Godfrey et al. (2014) that show these differences among course levels and this tendency towards improvement in written competence. The results obtained seem to confirm the assumption of much second language writing research that fluency, accuracy, syntactic and lexical complexity progress in parallel (Wolfe-Quintero et al., 1998) and contradict research by Navés et al., (2003). We observe a development for each of these measures, with the elder groups of learners being better in fluency and accuracy indicators, in lexical measures and in one grammatical measure.

Moreover, not only did the bilingual program third graders outperform non bilingual program third graders, but the former even outscored non-bilingual fourth graders despite them being a year younger, in the general quality of the composition, in sentence length, in the percentage of error-free sentences, in errors per word ratio, in the total number of connectors and in lexical complexity. These results are in line with those of Lasagabaster (2008) and Navés, and Victori (2010) that seem to indicate that the positive effects of bilingual education are evident even when the bilingual program students are a year younger than the control students are. From the results obtained, it can be concluded that when learners are at grade three and have received bilingual instruction they achieve a level higher than learners a grade ahead in all the domains of written competence analysed.

An unexpected result deserves further consideration. The most grammatically complex compositions as measured by the sentence complexity ratio are the ones written by 
non-bilingual students as compared to bilingual students and by third grade students when compared to fourth grade students. We examined the students' compositions again to try to explain these results and found that bilingual students' compositions showed different categories to express ideas, instead of using only clauses. They used certain nouns derived from verbs to express an idea or an event and some adjectives to express properties. It seems then that although their compositions are less structurally complex from the point of view of the number of clauses used, they tend to have deeper notional complexity. This explanation is obviously tentative and calls for further research.

3. There is a significant difference in written competence between men and women, with women surpassing men in both groups. However, this happens with more measures in the non-bilingual program group. This agrees with studies like the one by Merisuo-Storm (2007) that indicates that bilingual programs may help to balance English results on gender grounds. Further research is nevertheless needed to confirm this result.

4. With respect to the correlations between the writing measures used, all the variables turned out to be associated significantly with the general quality of the composition, in both groups, except for sentence length in the bilingual group. With respect to the measures of written competence, we obtain significant relationships between all the pairs studied, which supports previous studies (e.g. Carlisle 1989; Navés et al. 2003). From the results obtained, we can say that accuracy induce longer compositions, more lexically complex with a larger number of connectors. Longer compositions are also more lexically complex compositions with more connectors. More lexically complex compositions are also more grammatically complex as measured by the number of connectors. The negative relationship between sentence complexity ratio and the other measures seem to support our argument that more notionally complex compositions with fewer clauses may characterise the writing of better and older students.

\section{Conclusions}

Our results confirm the superiority in written competence of bilingual program students. There are two main reasons that may explain why these programs offer sound benefits in written competence to students. On the one hand, students in bilingual programs are more frequently exposed to the English language. On the other hand, bilingual settings, which involve integrating both content and language goals, seem to provide suitable contexts in which to develop written discourse. Bilingual programs share many aspects of Communicative Language Teaching, while emphasising academic content as the substance of the communication. This is supposed to make this communication more relevant and purposeful, which may offer the necessary conditions for effective learning to take place and for written competence to develop.

A trend of development in written competence from third to fourth grade is observed in both groups indicating that the measures of fluency, accuracy, grammatical and lexical complexity progress at the same rate and they are significantly correlated. As far as gender 
is concerned, the results obtained call for more research to confirm the possible benefits of bilingual programs to help eliminate the gender differences in foreign language learning.

Finally, we acknowledge some limitations of the present study. Although the groups of participants selected for the study were as homogeneous as possible, some variables such as out-of-school exposure to English or socio-cultural family background could not be controlled. Regarding linguistic competence, both groups were homogeneous in terms of the number of years they had been studying English and their starting English proficiency level (A1 to A2). However, no specific competence test was carried out previous to the research. New studies will therefore have to be carried out in the future taking these limitations into account, so as to confirm the results obtained in the present study.

\section{REFERENCES}

Babba, K. and Nitta, R. (2014). "Phase transitions in development of writing fluency from a dynamic systems perspective", in Language Learning, 64: 1-35.

Carlisle, R. (1989). "The writing of Anglo and Hispanic elementary school students on bilingual, submersion and regular programs", in Studies in Second Language Acquisition, 11, 3: $257-280$.

Coyle D. (2008). "CLIL-A pedagogical approach from the European perspective", in N. Van Deusen-Sholl and N. Hornberger (eds.), Encyclopedia of Language and Education. New York: Springer Media, 97-111.

Godfrey, L and Treacy, C. (2014). "Change in French second language writing in study abroad and domestic contexts", in Foreign Language Annals, 47, 1: 48-65.

Larsen-Freeman, D. (2006). "The Emergence of complexity, fluency, and accuracy in oral and written production of five Chinese learners of English”, in Applied Linguistics, 27, 4: 590-619.

Lasagabaster, D. (2008). "Foreign language competence in CLIL courses", in The Open Applied Linguistics Journal, 1: 31-42

Lorenzo, F. and Rodríguez, L. (2014). "Onset and expansion of L2 cognitive academic language proficiency in bilingual settings: CALP in CLIL", in System, 47: 64-72.

Marsh D. (2008). "Language awareness and CLIL", in J. Cenoz and N. Hornberger (eds.), Encyclopedia of Language and Education. New York: Springer Media, 233-246.

Navés, T. and Victori, M. (2010). "CLIL in Catalonia: an overview of research studies", in D. Lasagabaster and Y. Ruiz de Zarobe (eds.), CLIL in Spain: Implementation, Results and Teacher Training. Newcastle: Cambridge Scholars Publishing, 30-54.

Merisuo-Storm T. (2007). "Pupils' attitudes towards foreign-language learning and development of literacy skills in bilingual education", in Teaching Teacher Education, 23: 226-235.

Merisuo-Storm T. and Soininen, M. (2014). "Students' first language skills in bilingual education", in Mediterranean Journal of Social Sciences, 5, 22: 72-81.

Navés, T., Torras, M., and Celaya, M. (2003). "Long-term effects of an earlier start. Analysis of EFL written production", in EUROSLA Yearbook 3, 103-129.

Ruiz de Zarobe, Y. (2008). "CLIL and foreign language learning: A longitudinal study", in International CLIL Research Journal, 1, 1: 60-73. 
Weissberg, B. (2000). "Developmental relationships in the acquisition of English syntax", in Learning and Instruction, 10: 37-53.

Whittaker, R. Llinares, A., and McCabe, A. (2011). "Written discourse development in CLIL at secondary school", in Language Teaching Research, 15, 3: 343-362.

Wolfe-Quintero, K., Inagaki, S. and Kim, H. (1998). Second Language Development in Writing: Measures of Fluency, Accuracy, and Complexity. Hawai'i: University of Hawai'i at Manoa.

IGCSE mark schemes and examiner report (2008). Retrieved from: http://www.cie.org.uk/qualifications/academic/middlesec/igcse/subject?assdef_id=864. 